\title{
Commentary: Central-acting therapeutics alleviate respiratory weakness caused by heart failure-induced ventilatory overdrive
}

\author{
Amy M. Pastva ${ }^{1}$ and Julia K. L. Walker ${ }^{1,2 *}$ \\ ${ }^{1}$ Duke University School of Medicine, Duke University, Durham, NC, United States, ${ }^{2}$ Duke University School of Nursing, Duke \\ University, Durham, NC, United States
}

Keywords: respiratory muscle weakness, exercise training, heterodimer receptor, blood-brain barrier, ventilatory overdrive, angiotensin drive to breathe, GPCR signaling

\section{A commentary on}

Central-acting therapeutics alleviate respiratory weakness caused by heart failure-induced ventilatory overdrive

by Foster, A. J., Platt, M. J., Huber, J. S., Eadie, A. L., Arkell, A. M., Romanova, N., et al. (2017). Sci. Transl. Med. 9:eaag1303. doi: 10.1126/scitranslmed.aag1303

\section{OPEN ACCESS}

Edited by:

Gregory D. Funk,

University of Alberta, Canada

Reviewed by:

Ana Paula Abdala,

University of Bristol, United Kingdom

*Correspondence:

Julia K. L. Walker

walke082@mc.duke.edu

Specialty section:

This article was submitted to Respiratory Physiology,

a section of the journal

Frontiers in Physiology

Received: 02 January 2018 Accepted: 30 April 2018 Published: 23 May 2018

Citation:

Pastva AM and Walker JKL (2018)

Commentary: Central-acting

therapeutics alleviate respiratory

weakness caused by heart

failure-induced ventilatory overdrive.

Front. Physiol. 9:554.

doi: 10.3389/fphys.2018.00554
Heart failure (HF) is a chronic, progressive condition that manifests not only in cardiac dysfunction but also in respiratory dysfunction. Diaphragmatic myopathy is common and contributes to dyspnea and exercise intolerance in advancing stages of HF (reviewed in Cahalin and Arena, 2015; Dubé et al., 2016). The potential pathophysiological mechanisms driving diaphragmatic myopathy over the evolution of HF have remained elusive. Long-held views suggest that a HFinduced increase in lung mechanical load (either from pulmonary edema or lung fibrosis) is the primary cause of progressive diaphragmatic myopathy (Mahdyoon et al., 1989; Chomsky et al., 1997; Gheorghiade et al., 2010; Cahalin and Arena, 2015; Dubé et al., 2016). However, Foster et al. provide compelling evidence for an additional explanation (Foster et al., 2017). In the article "Central-acting therapeutics alleviates inspiratory weakness caused by HF-induced ventilatory overdrive" they elegantly demonstrate that initiation of diaphragmatic myopathy is mediated by a hormonal mechanism independent of lung mechanical load. They used two mouse models of pressure-overload-induced HF to show that activation of functionally codependent angiotensin type-1 $\left(\mathrm{AT}_{1}\right)$ receptors and beta-adrenergic receptors ( $\beta$-ARs) triggers an excessive central drive to breathe that underlies the development of diaphragm myopathy. This ventilatory (AbdAlla et al., 2005) overdrive was associated with increased mRNA expression of PERK (protein kinase R-like endoplasmic reticulum kinase), hyperphosphorylation-mediated inhibition of EIF2a (eukaryotic translation initiation factor $2 \alpha$ ) and consequent reduction in protein translation and cross-sectional area of the diaphragm. Given that only blood-brain-barrier (BBB)-permeant antagonists of the $\mathrm{AT}_{1}$ receptors and $\beta$-ARs were able to diminish diaphragmatic myopathy, Foster et al. concluded that receptors behind the $\mathrm{BBB}$ were responsible for ventilatory overdrive. These atrophic changes preceded detectible evidence of diaphragm force changes and weakness. Thus, ventilatory overdrive associated with HF may now be thought of, and perhaps treated, as an early hormonal complication of the disease.

In our opinion, the important therapeutic impact of the Foster et al., findings is twofold. First, their study provides rationale for early initiation of treatment to prevent ventilatory overdriveperhaps upon diagnosis of HF, but certainly well before lung structural or mechanical changes 
occur. Second, this work highlights the therapeutic importance of considering the BBB-permeant and other characteristics of $\mathrm{AT}_{1}$ receptor and $\beta \mathrm{AR}$ blockers used to treat $\mathrm{HF}$. Before commenting on the pharmacological aspects of the Foster manuscript it may be instructive to provide clarification of some of the complex terminology and concepts used in the manuscript.

\section{VENTILATORY DRIVE AND OVERDRIVE}

The drive to breathe is reflected by the frequency of action potentials that originate at the medullary respiratory center and are transmitted to the diaphragm via the phrenic nerve (Whitelaw et al., 1975). This drive to breathe is influenced by numerous types of sensory information, not the least of which is chemical. The main finding in the Foster et al. paper is that blockade of hormones typically elevated in HF significantly mitigates the increased drive to breathe and diaphragmatic weakening observed in their murine heart disease model.

Foster et al. use the term "ventilatory drive" to describe the drive to breathe but there are several other synonyms including central drive, neural drive, and respiratory drive. Because measurement of phrenic nerve activity, the most direct measure of ventilatory drive, is not feasible in humans and difficult in animals, minute ventilation can be used as a surrogate. However, in pathological conditions minute ventilation may not accurately reflect the drive to breathe (Celli et al., 1997). Thus, in disease states the ventilatory drive to the diaphragm can be inferred from the magnitude of respiratory pressure generated by the contracting muscle. In humans the pressure generated during the first $0.1 \mathrm{sec}$ of a very brief inspiratory occlusion $\left(\mathrm{P}_{0.1}\right)$ during a normal tidal breath reflects the ventilatory drive (Celli et al., 1997). In the Foster study ventilatory drive is approximated by the inspiratory pressure $\left(\mathrm{P}_{\mathrm{I}}\right)$, which was calculated from esophageal pressure measured during normal eupneic breathing in the anesthetized mouse.

Elevated mouth occlusion pressure $\left(\mathrm{P}_{0.1}\right)$ or inspiratory pressure $\left(\mathrm{P}_{\mathrm{I}}\right)$ reflects increased activation of the phrenic nerve and concomitant increased contraction of the diaphragm.

Diaphragmatic weakness is assessed in humans by voluntarily generating a maximal inspiratory pressure $\left(\mathrm{P}_{\mathrm{Imax}}\right)$ (Celli et al., 1997; Lin and Lin, 2012). Since a volitional maneuver is not feasible in mice, Foster et al. measured esophageal pressure during a $25 \mathrm{~s}$ tracheal occlusion in anesthetized mice $\left(\mathrm{P}_{\mathrm{IOOC}}\right)$. In summary, inspiratory pressure is directly proportional to ventilatory drive, maximal inspiratory pressure is inversely proportional to diaphragm weakness and, although the mechanisms are not well understood, chronic elevated ventilatory drive is associated with diaphragmatic weakness.

Foster et al. use the term "ventilatory overdrive" and define it as a persistent increase in ventilatory drive triggering diaphragmatic myopathy. This is a somewhat cumbersome definition, but deconstructed it essentially reflects the combination of both an increase in $\mathrm{P}_{\mathrm{I}}$ and a decrease in $\mathrm{P}_{\text {IOOC. }}$ The utility of this somewhat confusing term becomes apparent in the manuscript discussion where the focus rests on the effect of hormones to promote progressive diaphragmatic weakening associated with an increased drive to breathe.

\section{EARLY RAAS-TARGETED INTERVENTIONS TO COMBAT DIAPHRAGMATIC MYOPATHY}

Although $\mathrm{HF}$ is a heterogeneous condition with multiple etiologies, all etiologies lead to chronic activation of the reninangiotensin-aldosterone system (RAAS) and the sympathetic nervous system (McMurray et al., 2014; McMurray, 2015; Metra and Teerlink, 2017). The RAAS consists of a two-arm axis: an excitatory angiotensin II (ANGII)/AT ${ }_{1} \mathrm{R} / \mathrm{ACE}$ (angiotensin converting enzyme) arm and a protective AT2R/ACE2 arm. Increasing evidence suggests that in HF there is an imbalance to favor the excitatory arm, leading to sympathoadrenergic activation and that this imbalance is modulated in part in the cardiovascular-control regions of the brain (reviewed in Zucker et al., 2014). Therefore, the use of BBB permeant interventions that restore RAAS balance and/or cause sympathoinhibition are plausible therapeutic strategies. Certainly, the data in Foster et al. challenge us to consider the potential application of BBB permeant pharmacological interventions, especially early in the $\mathrm{HF}$ disease process, to inhibit $\mathrm{AT}_{1}$ receptor- and $\beta \mathrm{AR}$-stimulated ventilatory overdrive and mitigate diaphragmatic myopathy.

Nonpharmacological interventions such as physical exercise may also be important to consider as an early therapeutic strategy given its positive effects on mortality, morbidity, functional capacity, and quality of life in HF (De Maeyer et al., 2013). For instance, aerobic exercise has been shown to dampen RAAS and sympathoadrenergic activation and reduce the typically elevated circulating levels of ANGII and catecholamines characteristic of HF (Coats et al., 1992; Braith et al., 1999; Passino et al., 2006a,b; Gielen et al., 2010). Additionally, exercise has also been shown to dampen central RAAS activation (reviewed in Zucker et al., 2014). Thus, exercise may be an important therapeutic approach to mitigate respiratory dysfunction in HF via its inhibition of RAAS and catecholamines. Targeting the respiratory muscles themselves may also be beneficial given that inspiratory muscle strength is correlated with exercise capacity and peak oxygen consumption and is an independent predictor of survival (Meyer et al., 2001). For example, inspiratory muscle training using a threshold device, examined across multiple systematic reviews, has been shown to improve one or more pathophysiological manifestations of HF such as dyspnea, maximal inspiratory and expiratory pressures, respiratory muscle strength, muscle sympathetic activity, and exercise capacity (reviewed in Cahalin and Arena, 2015). Slow breathing exercises in patients with HF aims to reduce respiratory rate and improve dyspnea and exercise tolerance. It has been demonstrated to decrease chemoreflex activity to hypoxia and hypercapnia and increase baroreflex activity through improved vagal tone (Bernardi et al., 1998, 2002; Parati et al., 2008). Thus, centrally-targeted $\mathrm{AT}_{1}$ and $\beta A R$ receptor modulating pharmaceuticals in combination with physical exercise early in HF progression may combat ventilatory overdrive and mitigate respiratory muscle myopathy to improve 
HF symptomatology, exercise tolerance, and potentially severity classification.

\section{ANGII DRIVE TO BREATHE AND THE BLOOD BRAIN BARRIER}

The notion that ANGII regulates ventilation is not new. Potter and McCloskey (1979) and Alexander and Lumbers (1981) showed that ANGII stimulates the drive to breathe in anesthetized dogs. Subsequent studies showed this to also be true in dogs that were conscious-where arterial baroreflexes, not dampened by anesthesia, can inhibit ventilation (Ohtake and Jennings, 1993). When the blood pressure-raising effects of infusion of ANGII (a vasoconstrictor) were normalized by concomitant infusion of SNP (a vasodilator), the ANGIImediated drive to breathe was revealed to be quite pronounced (Ohtake et al., 1993). If this translates to humans, then pathologically elevated levels of ANGII may indeed cause ventilatory overdrive.

However, Foster et al., did not measure systemic or brain levels of ANGII, nor did they speculate about the specific central location at which ANGII acts to stimulate ventilation. In fact, they state that the ability of ANGII/catecholamines to cross the $\mathrm{BBB}$ is controversial. In conscious dogs, systemic-derived ANGII cannot cross the BBB; however, it is still able to centrally stimulate ventilation by activating circumventricular organ neurons which effectively lack a BBB but project to medullary cardiorespiratory control centers behind the BBB (Walker and Jennings, 1994). Because only BBB-permeant antagonists of the $\mathrm{AT}_{1}$ receptor and $\beta A R$ rescued the mice, Foster et al. concluded that receptors behind the $\mathrm{BBB}$ mediate ventilatory overdrive. An alternative explanation is possible in that the same molecular characteristics that enable an antagonist to cross the $\mathrm{BBB}$ may also allow it to regulate cell signaling downstream of the $\mathrm{AT}_{1}$ receptor/ $\beta \mathrm{AR}$ heterodimer in a unique way. If true, the BBB-permeant antagonists may have acted at circumventricular organ neurons, rather than those behind the $\mathrm{BBB}$, to exert an effect on ventilatory drive. Yet another possibility is that the chronic disease model [transverse aortic constriction (TAC)] employed in this study may have initiated changes in the heterodimer ratio of $\mathrm{AT}_{1}$ receptors to $\beta A R s$ that resulted in signaling changes at the diaphragm muscle cells themselves, or myopathy secondary to activation of ventilatory overdrive.

\section{G PROTEIN-COUPLED RECEPTOR THEORY}

$\beta A R$ and $A T_{1}$ receptor are two very well characterized $G$ protein-coupled receptors (GPCRs). GPCRs, the largest family of cell surface receptors, are implicated in numerous diseases and thus their signaling pathways are prime targets for therapeutic intervention (Lefkowitz, 2004). Intra- and intermolecular electrostatic forces determine the 3-dimensional shape of a receptor and thus, its function (Matthew, 1985). The current GPCR paradigm states that signaling is transduced by both a
G protein-dependent and a $G$ protein-independent/ßarrestindependent signaling pathway (Lefkowitz and Shenoy, 2005). For example, orthosteric binding of a ligand causes the receptor to shift into a shape which triggers $G$ protein- and/or Barrestindependent signaling (Lefkowitz, 2004). Moreover, each receptor ligand, based on its molecular structure, can activate these two signaling pathways with differing efficacies resulting in biased signaling of one pathway over the other. Also, exogenous drugs, endogenous molecules and ions that electrostatically interact with receptor regions (other than the binding pocket) act as allosteric modulators or receptor signaling. For example, $\mathrm{Zn} 2+$ enhances agonist affinity and second messenger signaling downstream of the $\beta 2 \mathrm{AR}$ (beta-2-adrenergic receptor) in membranes prepared from Sf9 cells (Swaminath et al., 2002).

Adding complexity to GPCR signaling mechanisms, we now know that two or more molecularly dissimilar and individually functional GPCRs can combine to form a receptor signaling complex that has a distinct pharmacology (Angers et al., 2002; Smith and Milligan, 2010; Rivero-Müller et al., 2013). GPCRs were typically thought of as monomers capable of signaling completely independently. Although the majority of receptors within a specific GPCR type do indeed function as monomers, a functionally relevant proportion of them can dimerize (Whorton et al., 2007). In 2003 Barki-Harrington et al. (2003) were the first to show that $\mathrm{AT}_{1}$ receptor and $\beta \mathrm{AR}$ heterodimerize. Moreover, they demonstrated that the tachycardic effect of isoproterenol was inhibited by either propranolol or valsartan in mice. Since publication of that seminal finding, numerous other investigators have described receptor heterodimerization (Barki-Harrington et al., 2003; Noma et al., 2007; Tilley, 2011; Siddiquee et al., 2013; Wilson et al., 2013). The electrostatic interactions derived from the close proximity of receptors within the heterodimer complex impacts receptor conformation and thus, signaling (Kenakin and Miller, 2010). Moreover, pathway intermediates downstream of one receptor can exert lateral allosterism on the other receptor in a heterodimer (Wilson et al., 2013). Taken together, receptor heterodimers are allosteric machines where activation of a receptor in its monomer form does not necessarily yield the same physiological outcome as its activation when complexed as a heterodimer (Goupil et al., 2013). Thus, alterations in the ratio of monomer to heterodimer may occur during times of stress and lead to pathogenesis. For example, angiotensin and bradykinin 2 receptor heterodimers sensitize vascular smooth muscle cells to the pro-contractile effects of ANGII (AbdAlla et al., 2000). This has been shown to contribute to experimental hypertension (AbdAlla et al., 2005) and human preeclampsia (AbdAlla et al., 2001). Additionally, the work from Siddiquee et al. (2013) concludes that loss of apelin or its receptor, which tonically inhibits $\mathrm{AT}_{1}$ receptor signaling as part of a heterodimer, may lead to pathogenesis in cardiovascular disease.

Although $\mathrm{AT}_{1}$ receptor and $\beta \mathrm{AR}$ transmodulation clearly underlies the results in the Foster et al., it is prudent to consider that biased cell signaling may also play a role through its effect on heterodimer signaling. Others have shown that $\left[\mathrm{Sar}^{1}, \mathrm{Ile}^{4}, \mathrm{Il}^{8}\right]$-ANGII (SII), a Barrestin-biased angiotensin receptor agonist, inhibits/dampens bradykinin 2 receptor signaling (Wilson et al., 2013). Thus, a ligand that 
triggers biased signaling at one heterodimer receptor type may in turn impact signaling of the second receptor type. This type of lateral allosterism may be at play in HF since carvedilol, and not metoprolol, is a weak agonist of $\beta$ arrestin-signaling,(Wisler et al., 2007) which could be contributing to ventilatory overdrive.

In summary, the current GPCR signaling paradigm suggests that a single ligand can trigger more than one signaling pathway downstream of a particular receptor ( $G$ protein and $\beta$ arrestin pathways), that these signaling pathways are not necessarily equally activated (biased signaling) and that signaling at one receptor can modulate the signaling at a second receptor family (heterodimer transmodulation). Regulation of GPCR signaling is extremely complex and our current understanding of how most pharmacologic drugs, including those used in this study, impact ßarrestin-dependent-, biased- and heterodimer-signaling is incomplete, as is the cell specificity of the drug effects. Moreover, how the ratio of monomer to heterodimer receptors may impact pathology (or vice-versa) is largely unexplored in the context of drug design. Although a daunting task, the design of novel molecules that have pluridimensional efficacies holds great promise for treatment of multiple morbidities

\section{REFERENCES}

AbdAlla, S., Abdel-Baset, A., Lother, H., el Massiery, A., and Quitterer, U. (2005). Mesangial AT1/B2 receptor heterodimers contribute to angiotensin II hyperresponsiveness in experimental hypertension. J. Mol. Neurosci. 26, 185-192. doi: 10.1385/JMN:26:2-3:185

AbdAlla, S., Lother, H., and Quitterer, U. (2000). AT1-receptor heterodimers show enhanced G-protein activation and altered receptor sequestration. Nature 407, 94-98. doi: $10.1038 / 35024095$

AbdAlla, S., Lother, H., el Massiery, A., and Quitterer, U. (2001). Increased AT1 receptor heterodimers in preeclampsia mediate enhanced angiotensin II responsiveness. Nat. Med. 7:1003. doi: 10.1038/nm0901-1003

Alexander, I. E., and Lumbers, E. R. (1981). The effects of angiotensin on respiratory patterns of anaesthetized dogs. Respir. Physiol. 46, 261-270. doi: 10.1016/0034-5687(81)90126-2

Angers, S., Salahpour, A., and Bouvier, M. (2002). Dimerization: an emerging concept for $G$ protein-coupled receptor ontogeny and function. Annu. Rev. Pharmacol. Toxicol. 42, 409-435. doi: 10.1146/annurev.pharmtox.42.091701.082314

Barki-Harrington, L., Luttrell, L. M., and Rockman, H. A. (2003). Dual inhibition of $\beta$-adrenergic and angiotensin II receptors by a single antagonist. a functional role for receptor-receptor interaction in vivo. Circulation 108, 1611-1618. doi: 10.1161/01.CIR.0000092166.30360.78

Bernardi, L., Porta, C., Spicuzza, L., Bellwon, J., Spadacini, G., Frey, A. W., et al. (2002). Slow breathing increases arterial baroreflex sensitivity in patients with chronic heart failure. Circulation 105, 143-145. doi: 10.1161/hc0202.103311

Bernardi, L., Spadacini, G., Bellwon, J., Hajric, R., Roskamm, H., and Frey, A. W. (1998). Effect of breathing rate on oxygen saturation and exercise performance in chronic heart failure. Lancet 351, 1308-1311. doi: 10.1016/S0140-6736(97)10341-5

Braith, R. W., Welsch, M. A., Feigenbaum, M. S., Kluess, H. A., and Pepine, C. J. (1999). Neuroendocrine activation in heart failure is modified by endurance exercise training. J. Am. Coll. Cardiol. 34, 1170-1175. doi: 10.1016/S0735-1097(99)00339-3

Cahalin, L. P., and Arena, R. A. (2015). Breathing exercises and inspiratory muscle training in heart failure. Heart Fail. Clin. 11, 149-172. doi: 10.1016/j.hfc.2014.09.002 associated with complex diseases such as HF and diaphragmatic myopathy.

\section{CONCLUSION}

The Foster et al., study significantly advances our understanding of diaphragmatic myopathy and helps to reconcile why various drugs with comparable cardiovascular effects can have differing benefits on symptomatology and mortality and reveal potential pathways for early intervention and future translational investigations.

\section{AUTHOR CONTRIBUTIONS}

All authors listed have made a substantial, direct and intellectual contribution to the work, and approved it for publication.

\section{FUNDING}

The authors gratefully receive support from NIH grants R01 AI110007 (JW) and R01AG045551, P30AG028716 (AP).

Celli, B. R., De Oca, M. M., Mendez, R., and Stetz, J. (1997). Lung reduction surgery in severe COPD decreases central drive and ventilatory response to $\mathrm{CO}_{2}$. CHEST 112, 902-906. doi: 10.1378/chest.112.4.902

Chomsky, D. B., Lang, C. C., Rayos, G., and Wilson, J. R. (1997). Treatment of subclinical fluid retention in patients with symptomatic heart failure: effect on exercise performance. J. Heart Lung Transplant. 16, 846-853.

Coats, A. J., Adamopoulos, S., Radaelli, A., McCance, A., Meyer, T. E., Bernardi, L., et al. (1992). Controlled trial of physical training in chronic heart failure. exercise performance, hemodynamics, ventilation, and autonomic function. Circulation 85, 2119-2131. doi: 10.1161/01.CIR.85.6.2119

De Maeyer, C., Beckers, P., Vrints, C. J., and Conraads, V. M. (2013). Exercise training in chronic heart failure. Ther. Adv. Chronic Dis. 4, 105-117. doi: $10.1177 / 2040622313480382$

Dubé, B. P., Agostoni, P., and Laveneziana, P. (2016). Exertional dyspnoea in chronic heart failure: the role of the lung and respiratory mechanical factors. Eur. Respir. Rev. 25, 317-332. doi: 10.1183/16000617.0048 $-2016$

Foster, A. J., Platt, M. J., Huber, J. S., Eadie, A. L., Arkell, A. M., Romanova, N., et al. (2017). Central-acting therapeutics alleviate respiratory weakness caused by heart failure-induced ventilatory overdrive. Sci. Transl. Med. 9:eaag1303. doi: 10.1126/scitranslmed.aag1303

Gheorghiade, M., Follath, F., Ponikowski, P., Barsuk, J. H., Blair, J. E., Cleland, J. G., et al. (2010). Assessing and grading congestion in acute heart failure: a scientific statement from the acute heart failure committee of the heart failure association of the European Society of Cardiology and endorsed by the European Society of Intensive Care Medicine. Eur. J. Heart. Fail. 12, 423-433. doi: 10.1093/eurjhf/hfq045

Gielen, S., Schuler, G., and Adams, V. (2010). Cardiovascular effects of exercise training: molecular mechanisms. Circulation 122, 1221-1238. doi: 10.1161/CIRCULATIONAHA.110.939959

Goupil, E., Laporte, S. A., and Hébert, T. E. (2013). GPCR heterodimers: asymmetries in ligand binding and signalling output offer new targets for drug discovery. Br. J. Pharmacol. 168, 1101-1103. doi: 10.1111/bph.12040

Kenakin, T., and Miller, L. J. (2010). Seven transmembrane receptors as shapeshifting proteins: the impact of allosteric modulation and functional selectivity on new drug discovery. Pharmacol. Rev. 62, 265-304. doi: $10.1124 /$ pr.108.000992 
Lefkowitz, R. J. (2004). Historical review: a brief history and personal retrospective of seven-transmembrane receptors. Trends Pharmacol. Sci. 25, 413-422. doi: $10.1016 /$ j.tips.2004.06.006

Lefkowitz, R. J., and Shenoy, S. K. (2005). Transduction of Receptor Signals by ß-Arrestins. Science 308, 512-517. doi: 10.1126/science.1109237

Lin, C. K., and Lin, C. C. (2012). Work of breathing and respiratory drive in obesity. Respirology 17, 402-411. doi: 10.1111/j.1440-1843.2011.02124.x

Mahdyoon, H., Klein, R., Eyler, W., Lakier, J. B., Chakko, S. C., and Gheorghiade, M. (1989). Radiographic pulmonary congestion in end-stage congestive heart failure. Am. J. Cardiol. 63, 625-627. doi: 10.1016/0002-9149(89) 90912-0

Matthew, J. B. (1985). Electrostatic effects in proteins. Annu. Rev. Biophys. Biophys. Chem. 14, 387-417. doi: 10.1146/annurev.bb.14.060185.002131

McMurray, J. J. (2015). Neprilysin inhibition to treat heart failure: a tale of science, serendipity, and second chances. Eur. J. Heart Fail. 17, 242-247. doi: 10.1002/ejhf.250

McMurray, J. J., Packer, M., Desai, A. S., Gong, J., Lefkowitz, M. P., Rizkala, A. R., et al. (2014). Angiotensin-neprilysin inhibition versus enalapril in heart failure. N. Engl. J. Med. 371, 993-1004. doi: 10.1056/NEJMoa1409077

Metra, M., and Teerlink, J. R. (2017). Heart failure. Lancet 390, 1981-1995. doi: 10.1016/S0140-6736(17)31071-1

Meyer, F. J., Borst, M. M., Zugck, C., Kirschke, A., Schellberg, D., Kübler, W., et al. (2001). Respiratory muscle dysfunction in congestive heart failure: clinical correlation and prognostic significance. Circulation 103, 2153-2158. doi: 10.1161/01.CIR.103.17.2153

Noma, T., Lemaire, A., Naga Prasad, S. V., Barki-Harrington, L., Tilley, D. G., Chen, J., et al. (2007). $\beta$-Arrestin-mediated $\beta(1)$-adrenergic receptor transactivation of the EGFR confers cardioprotection. J. Clin. Invest. 117, 2445-2458. doi: 10.1172/JCI31901

Ohtake, P. J., and Jennings, D. B. (1993). Angiotensin II stimulates respiration in awake dogs and antagonizes baroreceptor inhibition. Respir. Physiol. 91, 335-351. doi: 10.1016/0034-5687(93)90110-V

Ohtake, P. J., Walker, J. K., and Jennings, D. B. (1993). Renin-angiotensin system stimulates respiration during acute hypotension but not during hypercapnia. J. Appl. Physiol. 74, 1220-1228. doi: 10.1152/jappl.1993. 74.3.1220

Parati, G., Malfatto, G., Boarin, S., Branzi, G., Caldara, G., Giglio, A., et al. (2008). Device-guided paced breathing in the home setting: effects on exercise capacity, pulmonary and ventricular function in patients with chronic heart failure: a pilot study. Circ. Heart Fail. 1, 178-183. doi: 10.1161/CIRCHEARTFAILURE.108.772640

Passino, C., Poletti, R., Bramanti, F., Prontera, C., Clerico, A., and Emdin, M. (2006b). Neuro-hormonal activation predicts ventilatory response to exercise and functional capacity in patients with heart failure. Eur. J. Heart Fail. 8, 46-53. doi: 10.1016/j.ejheart.2005.05.007

Passino, C., Severino, S., Poletti, R., Piepoli, M. F., Mammini, C., Clerico, A., et al. (2006a). Aerobic training decreases B-type natriuretic peptide expression and adrenergic activation in patients with heart failure. J. Am. Coll. Cardiol. 47, 1835-1839. doi: 10.1016/j.jacc.2005.12.050

Potter, E. K., and McCloskey, D. I. (1979). Respiratory stimulation by angiotensin II. Respir. Physiol. 36, 367-373. doi: 10.1016/0034-5687(79)90048-3
Rivero-Müller, A., Jonas, K. C., Hanyaloglu, A. C., and Huhtaniemi, I. (2013). "Di/oligomerization of GPCRs-mechanisms and functional significance," in Progress in Molecular Biology and Translational Science, Vol. 117, eds J. Giraldo and F. Ciruela (Elsevier Inc.), 163-185. doi: 10.1016/B978-0-12-386931-9.00007-6

Siddiquee, K., Hampton, J., McAnally, D., May, L. T., and Smith, L. H. (2013). The apelin receptor inhibits the angiotensin II type 1 receptor via allosteric trans-inhibition. Br. J. Pharmacol. 168, 1104-1117. doi: 10.1111/j.1476-5381.2012.02192.x

Smith, N. J., and Milligan, G. (2010). Allostery at G protein-coupled receptor homo- and heteromers: uncharted pharmacological landscapes. Pharmacol. Rev. 62, 701-725. doi: 10.1124/pr.110.002667

Swaminath, G., Steenhuis, J., Kobilka, B., and Lee, T. W. (2002). Allosteric modulation of $\beta 2$-adrenergic receptor by Zn2+. Mol. Pharmacol. 61, 65-72. doi: $10.1124 / \mathrm{mol} .61 .1 .65$

Tilley, D. G. (2011). Functional relevance of biased signaling at the angiotensin II Type 1 receptor. Endocr. Metab. Immune Disord. Drug Targets 11, 99-111. doi: $10.2174 / 187153011795564133$

Walker, J. K., and Jennings, D. B. (1994). Angiotensin mediates stimulation of ventilation after vasopressin V1 receptor blockade. J. Appl. Physiol. 76, 2517-2526. doi: 10.1152/jappl.1994.76.6.2517

Whitelaw, W. A., Derenne, J. P., and Milic-Emili, J. (1975). Occlusion pressure as a measure of respiratory center output in conscious man. Respir. Physiol. 23, 181-199. doi: 10.1016/0034-5687(75)90059-6

Whorton, M. R., Bokoch, M. P., Rasmussen, S. G., Huang, B., Zare, R. N., Sunahara, R. K. et al. (2007). A monomeric $G$ protein-coupled receptor isolated in a highdensity lipoprotein particle efficiently activates its G protein. Proc. Natl. Acad. Sci. U.S.A. 104, 7682-7687. doi: 10.1073/pnas.0611448104

Wilson, P. C., Lee, M. H., Appleton, K. M., El-Shewy, H. M., Morinelli, T. A., Jaffa, A. A. et al. (2013). The arrestin-selective angiotensin AT(1) receptor agonist [Sar(1),Ile(4),Ile(8)]-AngII negatively regulates bradykinin $\mathrm{B}(2)$ receptor signaling via $\mathrm{AT}(1)-\mathrm{B}(2)$ receptor heterodimers. J. Biol. Chem. 288, 18872-18884. doi: 10.1074/jbc.M113.472381

Wisler, J. W., DeWire, S. M., Whalen, E. J., Violin, J. D., Drake, M. T., Ahn, S., et al. (2007). A unique mechanism of $\beta$-blocker action: carvedilol stimulates $\beta$-arrestin signaling. Proc. Natl. Acad. Sci. U.S.A. 104, 16657-16662. doi: 10.1073/pnas.0707936104

Zucker, I. H., Xiao, L., and Haack, K. K. (2014). The central renin-angiotensin system and sympathetic nerve activity in chronic heart failure. Clin. Sci. 126, 695-706. doi: 10.1042/CS20130294

Conflict of Interest Statement: The authors declare that the research was conducted in the absence of any commercial or financial relationships that could be construed as a potential conflict of interest.

Copyright $\odot 2018$ Pastva and Walker. This is an open-access article distributed under the terms of the Creative Commons Attribution License (CC BY). The use, distribution or reproduction in other forums is permitted, provided the original author(s) and the copyright owner are credited and that the original publication in this journal is cited, in accordance with accepted academic practice. No use, distribution or reproduction is permitted which does not comply with these terms. 